\title{
Introducing Changemaking Engineering into an Operations Research Course: Some Unexpected Results
}

\section{Dr. Rick Olson, University of San Diego}

Rick T. Olson is Associate Dean in the Shiley-Marcos School of Engineering at the University of San Diego. His research interests lay in engineering student persistence, and applied operations research. $\mathrm{He}$ is active in outreach activities targeting underrepresented populations and has received NSF funding to support U.S. military veterans, community college transfer students, and innovative engineering education. He has a B.S. in Mechanical Engineering, and M.S. in Industrial Engineering, and a Ph.D. in Mechanical Engineering with emphasis in Operations Research from the University of Illinois at UrbanaChampaign.

\section{Mr. Andrés Esteban Acero, Universidad de los Andes}

Andrés Acero is a PhD Candidate of Engineering at Universidad de los Andes, Colombia. He holds a bachelor's and master's degree on Industrial Engineering from the same academic institution. His research interest lie in the area of applications of social justice, engineering education and systems science, ranging from theory to modelling to implementation. In recent years, he has focused on natural resources management, active learning and waste management on emergent economies. Andrés is an active member of Ingenieros sin Fronteras Colombia since 2012, and he had worked on several engineering projects with social impact. In addition, he has collaborated with researchers of the Laboratory of Cognition at Universidad de los Andes, particularly in decision-making processes and teamwork. He is co-founder of INTERACT, a research group on complex adaptive systems and social network analysis. 


\title{
Introducing Changemaking Engineering into an Operations Research Course: Some Unexpected Results
}

\begin{abstract}
With funding from a National Science Foundation (NSF) IUSE/PFE REvolutionizing engineering and computer science Departments (RED) grant, the Shiley-Marcos School of Engineering at the University of San Diego is working to produce and disseminate a model for redefining the engineering education canon with the goal of developing "Changemaking Engineers." One of the strategies for achieving this goal is to infuse traditional engineering classes with new materials that address this changemaking theme. The goal is for students to develop the same fundamental skills that they currently acquire, but to see better how these skills can be applied to problems and situations that don't appear in traditional textbooks. This greater perspective will encourage some students to pursue non-traditional career paths, and other to practice with greater awareness of the impact of engineering on society.

In Fall 2017, changemaking engineering was introduced into the required deterministic operations research (OR) course taken by industrial and systems engineers at our university. Some changemaking elements were added to lectures, and the authors created a series of assignments that asked the students to think about the nexus of changemaking and operations research. Through this exercise, we learned that some assumptions about the student perspectives of changemaking, and even operations research were wrong. Some students considered any change, good or bad, to constitute changemaking. And students had many difficulties identifying problems where OR could be applied and conflated OR with other areas of engineering practice. This has caused us to rethink whether the course empowers students in the ways that it is intended to, and to propose restructuring the course for future offerings.
\end{abstract}

\section{Introduction}

Most of the time spent in typical engineering classes is devoted to teaching discipline-specific technical skills, with less emphasis on the contexts in which engineering is practiced, and little focus on critical examinations of assumptions made during that engineering practice. This model has resulted in engineers who are proficient at solving problems within traditional areas of practice, but who may be ill prepared to assess the broader impact of their work, or to address new challenges outside of the fields discussed in their courses. With funding from a National Science Foundation (NSF) IUSE/PFE REvolutionizing engineering and computer science Departments (RED) grant, the Shiley-Marcos School of Engineering (SMSE) at the University of San Diego (USD) is working to produce and disseminate a model for redefining the "engineering canon" with the goal of developing "Changemaking Engineers." This revised canon will present technical skills within a contextual framework that includes humanitarian, sustainable, and social justice approaches. This broader perspective of engineering practice will produce graduates who can address a wider range of societal problems bringing new perspectives to traditional areas.

One of the strategies used to achieve the project goals is to infuse traditional engineering classes with new materials that address this changemaking theme. The goal is for students to develop the same fundamental skills that they currently learn, but to see how these skills can be applied to problems and situations that don't appear in traditional textbooks. By placing the technical concepts in new contexts, students will learn to critically evaluate the impact of their work in 
new ways, and they will graduate with a better understanding of their potential to use engineering to create change. For industrial engineers and systems engineering (ISyE) majors, this presents an opportunity to include examples of ISyE outside of traditional manufacturing, supply chain, or healthcare settings to show how the field can to address broader societal problems.

In Fall 2017, this changemaking content was introduced to ISYE 340, the required deterministic operations research (OR) course taken by ISyE majors with some positive results. However, the experience also revealed that student perceptions of what constitutes changemaking engineering did not match the instructor's expectations. It also showed that, although students are able to perform the mechanics of operations research, and model problems that are similar to the problems presented in the lecture, they are much less skilled at identifying new situations where OR can be applied.

This paper will summarize how changemaking was introduced into ISYE 340, and will summarize the activities that were used to contextualize some operations research models in humanitarian and social justice settings. An assignment that required students to identify opportunities where OR could be used to create positive change is discussed. This exercise also revealed important gaps in student understanding of the types of problems that can be addressed using OR. This misunderstanding will be used to drive changes in the future offerings of the course, and serve as a reminder that faculty sometimes make assumptions about student learning that are not correct.

\section{Background on the University of San Diego}

The University of San Diego is a private school with a liberal arts tradition. Addressing social issues in the classroom is an important part of the school's identity. Community service-learning has been practiced since the early 1990's, USD is recognized as a Community Engagement Institution by the Carnegie Foundation [1], and we are a member of Ashoka's Changemaker Campus Consortium [2]. From their first days on campus, students are told that they have the potential to be changemakers who make the world better.

Electrical engineering began in 1987, industrial engineering was added in 1996, and mechanical engineering was added in 2003. In 2013 the Shiley-Marcos School of Engineering was established. A general engineering program was created in 2016. A unique characteristic of all engineering degree programs is that they include the same liberal arts core required of all undergraduates. This results in 147 semester-unit engineering curricula that culminates in a dual Bachelor of Science/Bachelor of Arts degree. Computer science is also housed in SMSE, having moved from the College of Arts and Sciences in 2016. In Fall 2017 there were approximately 750 engineering and computer science majors; 105 of those were declared as ISyE majors.

The ISyE program offers a broad, general exposure to the field with no concentrations. After two years of general science and engineering classes students have required coursework in work analysis, manufacturing, quality, systems, and operations research. The OR component comprises separate deterministic and stochastic courses, discrete event simulation, and a course in operations/supply chain. 


\section{Developing Changemaking Engineers}

In 2014, the National Science Foundation (NSF) initiated the IUSE/PFE: REvolutionizing engineering and computer science Departments (IUSE/PFE: RED) program. The goals of this program (hereinafter referred to as RED) are to "enable engineering and computer science departments to lead the nation by successfully achieving significant sustainable changes necessary to overcome longstanding issues in their undergraduate programs and educate inclusive communities of engineering and computer science students prepared to solve $21^{\text {st }}$ century challenges."'[3] Awards have been made to three cohorts in the summers of 2015, 2016, and 2017 [4]. The school of engineering proposed the project Developing Changemaking Engineers which was funded in the first year of the program [5]. The first author of this paper is a Co-PI on the grant.

Consistent with the mission of the university, the project proposes to establish a foundation for a revised engineering canon that goes beyond the usual emphasis on disciplinary engineering to include broader understanding of the ways that successful engineers can work to achieve transformative results in all areas of society. This canon will help students to develop the knowledge and skills needed to apply their technical knowledge to promote social change in many areas including social justice, humanitarian advancement, and sustainable practices. Though some students may choose to work in these areas, it is expected that most will continue to work in traditional engineering jobs for private sector corporations. For those students, exposure to the changemaking contexts will make them better able to more fully assess the impact of their work on society. This understanding may influence which problems they decide are the most important, and which solutions they pursue. It is also expected that this revised canon will bring new students to engineering who will be attracted by the opportunity to use their education to become changemaking engineers.

Central to the vision of a revised engineering canon is the idea that the changemaking contexts will be integrated within traditional engineering courses without sacrificing essential technical content. For example, ergonomic analysis might be conducted through the lens of migrant farm workers, and the impact of social justice considerations may be included in cost/benefit analysis in an engineering economy course.

\section{ISYE 340}

ISYE 340 is a deterministic OR course taught using Winston's text [6]. As is the case with many junior-level introductory courses, it emphasizes linear programming (LP) and introduces students to the simplex method, sensitivity analysis, and modeling. The emphasis of the first half of the course is on the mathematics of solving LPs. The second half is dominated by modeling topics including allocation problems, common networks, integer models and goal programming. The high-level learning objectives for the course are that students completing the course should be able to:

1. Develop deterministic linear programming and network models to address common ISyE problems.

2. Recognize and identify the underlying mathematical structure of Linear Programming (LP), Integer Programming (IP), and common network models. 
3. Explain the principles behind the simplex method for solving linear programming models, execute the algorithm and interpret the solution.

4. Use the revised simplex method to solve LPs.

5. Perform sensitivity analysis of LP solutions.

6. Explain the principle of duality and apply it to help model, solve, and interpret LPs.

7. Select, apply and interpret an appropriate solution technique to solve common network models.

8. Use computer tools to solve optimization models and interpret the output.

In Fall 2017, 27 ISyE juniors and four mechanical engineers from our school took ISYE 340 along with five exchange students from Spain. The course was taught by the first author. The second author was a visiting scholar who spent several months on our campus. He is an industrial engineer with research interests in engineering and social justice. Consistent with the vision of introducing changemaking themes in required classes in the majors, the initial plan was to do this in several ways including:

- Introducing some lecture topics in the context of changemaking

- Rewriting some homework problems to include themes related to changemaking

- Create two new cases with social justice, humanitarian, or sustainability foundations

In the end, these goals proved to be overambitious. The first goal was met with modest success, but the last goals proved too difficult for reasons that will be discussed below. Instead, a new series of assignments asked students to reflect on their understanding of what it means to be a changemaking engineer, and to identify situations where the methods and models of ISYE 340 could be used to effect positive change.

\section{Revising Lecture Materials}

To meet the goals of the RED project, RED topics should be introduced into the course while continuing to meet the primary course learning objectives. One way to achieve this is to introduce common OR models by using RED contexts. For example, the characteristics of LPs might be introduced using a two-variable example of growing corn or wheat with limited resources of time, water and fertilizer. The scenario is easily understood but might seem quaint to U.S. students who envision large industrial farms that are more complex and entail more resources and constraints. But if the problem is reframed in the context of a subsistence farmer in the developing world, the problem takes on more immediacy and scope of the problem may seem more realistic, though it still omits many real-world considerations.

Three specific topics were introduced using changemaking contexts in Fall 2017. The first was developing LPs for creating personnel scheduling applications. In previous years, these models were introduced with a simple help-line staffing problem extracted from a textbook. Instead, the Crisis Text Line (CLT) [7] was used to motivate the example. CTL is a crisis intervention hotline that conducts its work through text messages. Most users are teens for whom text messaging is second nature. Every day, CTL receives more than 15,000 texts about problems ranging from relationship concerns, to depression, to suicidal ideation. There are more than 600 counselors in the program, and 50 may work at any time. In ISYE 340 the purpose of the CTL was introduced and students were asked what kinds of issues might be considered when creating a staffing schedule. Although an LP for this situation was not developed, it did motivate the broader topic 
of personnel scheduling, as the class moved on to developing an LP for scheduling nurses with differing skills in a hospital.

The Transportation Problem is a classic model taught in first OR classes. In the past, the scenario used considered a company with three factories trying to ship a product to four warehouses. Again, the problem is easily understood, but is overly simplistic. Why are there only four warehouses? How does the product get to the stores? Why does this company only make one product? To reframe the problem in a RED context, the transportation problem was introduced as an emergency logistics problem where supplies will be delivered from four U.S. military bases, to four zones in Asia from India to Japan. The background for the scenario was derived from a thesis at the Naval Postgraduate School [8]. Using humanitarian logistics as the motivation enabled a discussion of different objectives that can be encountered besides the most common goal of minimizing shipping costs. Shipping a single product became reasonable, because in this situation the shipping units are "Pack-Up-Kit" containers than contain a variety of relief supplies. The final problem was still simplified compared to the real situations encountered in relief operations, but choosing a humanitarian scenario as the framework for the transportation problem highlighted that OR can be used to provide compassionate service. Students were still exposed to commercial applications of the transportation model through extensions to transshipment scenarios, and homework.

Changemaking scenarios often have non-economic objectives, and conflicting objectives. In ISYE 340, these kinds of conflicts were introduced through a discussion of allocating water in the Colorado River Watershed. The Colorado River provides water to seven U.S. and two Mexican states. Farmers want water for their fields, but Phoenix and southern California want the water for residential and industrial uses. Water agencies want to maximize their revenue, but also the social benefits they provide, all while minimizing distribution costs. A city might want to maximize the total number of people served by a facility, but also maximize the number lowincome residents who receive the service.

After students were given a brief introduction to the watershed, they were asked to identify competing uses for the water, and different goals governments could have when allocating the water to different agencies. Besides the physical allocation questions, they were asked to consider who decides how the water should be used and whether the voices of all the users are likely to have been given equal consideration. Then, goal programming was introduced as one strategy that can be used to consider situations that have multiple objectives. Students were able to see how differing opinions of the importance of goals can be incorporated into the model, and how they affect the "optimal" decision.

Students learned the same elements of personnel scheduling, the transportation problem, and goal programming in Fall 2017 that they did in the past. But by introducing these topics in context of crisis lines, humanitarian relief, and natural resource allocation, students were made more aware of the "non-commercial" opportunities to use OR. The expectation was that this will broaden their understanding of how OR can be used and better enable them to be changemaking engineers.

\section{Changing Course Plans}


As the semester progressed, the initial plans of creating new homework problems and cases as means to introduce changemaking OR were changed. The pace of the class made it difficult to write homework problems that would both include changemaking context and adequately reinforce the lecture material. Some topics (e.g. mechanics of the simplex method) are purely mathematics and aren't related to social themes. In other situations, (e.g. sensitivity analysis), it proved difficult to create problems with numbers that illustrated the most important quantitative principles during the semester. As themes for cases were considered, real-world scenarios that could illustrate changemaking OR were identified, but they most often required integer models, had multiple objectives, or used other methods that students would not see until the end of the course. Resolving these obstacles will be discussed later in the paper.

Instead of adding the new problems and cases, new assignments were created that asked students to consider the potential of operations research to have significant social impact. Students reflected individually on the meaning of changemaking engineering, then worked in teams to identify situations where OR could be used to create change, and present some of their ideas to the class. In this way, student were encouraged the think about the potential of OR without being constrained by the limits of their technical skills.

\section{First Assignment: Defining Changemaker Engineer}

The first assignment was:

Define what it means to be a changemaking engineer, in your words. I am not interested in your understanding of the Ashoka definition of changemaker, or whether your personal perspective aligns with USD's, or the School of Engineering's mission. I want to know what the phrase means to you. You might state how you think Changemaking Engineers are different than "typical" engineers. If you think that all engineers are changemakers, please say why that is true.

There is no expected answer for this part of the assignment. You may be as brief, or as expansive as you wish to be, but I would like to be able to understand your perspective (and how it may be different than that of the person sitting next to you).

This assignment was intentionally open-ended. At USD, students are told that they can be changemakers from their first days on campus. There are many programs related to changemaking on campus. A Culture of Engagement is part of the university's vision and practicing changemaking is one of the pathways used to achieve that vision [9]. But engineering is not an explicit part of those statements. This assignment would help to understand how students perceive the relationship between engineering and changemaking.

Twenty-eight of the thirty-six students in the class completed this assignment. Their responses revealed a wide range of perspectives with the level of appropriation of the concept of changemaking engineering expressed along a continuum. As pointed out by Kabo and Baillie [10], concepts such as social justice, sustainability, humanitarian practices or ethics can be threshold concepts to define what a changemaking engineer is. Using this idea, the authors created three distinct categories to classify how students defined changemaking engineering. The first group represents students who did not relate engineering and changemaking in ways that reflect the perspective of the university, or the RED project. These students did not relate 
engineering with changemaking or by defined every engineer as a changemaker. Nine (32\%) students were in this groups. Their responses included statements like:

"I believe that all engineers are changemakers. This is not because every engineer will do something incredibly impactful environmentally or socially during their career. However, I think every engineer does impact their surroundings...."

And:

"In my opinion, a change maker engineer is an engineer that uses the knowledge that he gets from his experience as an engineering student to create a difference in the world and that can be in both directions, good and bad...."

A second group of students showed naïve understanding of the concept of changemaking. They expressed the importance of positive change and action for the social good, but they didn't directly relate the engineering with social change. Thirteen students were in this group (46\%). Examples of these statements include (italics ours): "Even though engineers are not exactly scientists, they use it to find efficient solutions to certain problems in order to make society better", and "I believe many engineers go into the profession to make money. Obviously, we all need money to live but I believe it would be hard to be focused on money and trying to help society at the same time. I believe this is the main difference between "typical" engineers and changemaker engineers."

Finally, six students (21\%) aligned changemaking with the vision of the RED team, the Ashoka changemaking campus, and, more than that, with their own engineering practice. Representative statements are:

“.... For an engineer, any effort against this inequality should be considered as a primary changemaking opportunity. Changemaking should not be limited to supporting humanitarian goals directly. Ensuring the accessibility of any form of advancement in the quality of life to everyone without any discriminations (including wealth) should be considered as changemaking within the enterprises as well."

And:

"To me, changemaking is all about taking action, small or large, to change the world. For example, a changemaker can be someone who advocates for the marginalized or someone who dedicates their life to serving others."

These student definitions are revealing because they show that despite being surrounded by a changemaking ethos on campus that relates changemaking to social issues, the engineers in ISYE 340 do not associate changemaking engineering with those issues directly. Their more general interpretation of changemaking engineering influenced their submissions on the next assignment where they were asked to think of ways to apply operations research to achieve societal change.

\section{Second Assignment: Changemaking using Operations Research}

As a prelude to the second assignment, the second author came to class and gave a brief lecture on how operations research can be used to promote change and social justice by addressing difficult problems that aren't related to the business operations that dominate OR in textbooks. As an example, he discussed the problem of placing sex offenders back in the community. He mentioned that there can be conflicting objectives (e.g. minimizing residential exposure versus not putting all offenders in one area), and many constraints including separation from some 
facilities, the amount of available housing, budgets for relocation, etc. He also emphasized that addressing social problems often requires data from a wide range of sources and input from specialists in nontechnical fields.

Students were then told the second assignment. In teams of four students they were to:

A: Identify 20 situations where OR could be used to create positive social change, summarizing these as short phrases. E.g. "Allocate organ transplants more equitably", or "Develop a tool to match volunteers with organizations that need their skills."

B: Write a 400 to 600 -word paper that elaborates on one of the situations identified in part A including a discussion of:

- The problem being addressed

- The population that would benefit

- Other people who would be affected

- Objectives that could be considered and whether they might conflict with each other

- The kinds of constraints that could be encountered.

$\mathrm{C}$ : Prepare and deliver a 3 to 5 -minute presentation to the class that summarizes the paper written in part B.

In parts $\mathrm{B}$, and $\mathrm{C}$, students were told to not attempt to model their scenario. It was anticipated that many of the problems students proposed could not be addressed with the modeling skills that student had developed. Furthermore, the kinds of ideas that students had for how the OR might be used was more important than their actual execution; the student's ideas were not to be restricted by limits in their technical skills.

To provide students with an example, the second author gave a 5-minute presentation proposing that a municipality could use operations research to determine whether to buy abandoned, foreclosed homes in the community and convert them to low-income housing or other uses. In the process, he noted that empty houses can lead to neighborhood decay and many associated problems that affect the residents and businesses in the neighborhood, and the surrounding community. He mentioned that constraints could include the city's budget for acquiring the properties, metrics of fairness in which neighborhoods are developed, a recognition that there may be threshold values for the fraction of a neighborhood that can be abandoned before problems begin to appear, and other considerations.

In their submissions, the teams contributed 184 responses revealing a wide range of contexts. Each response was mapped to one of eight categories of engineering practice that have been used in other reports for the school [11], or in the categories "Not Included/Unclear", or "Not an engineering practice." Where a response could be associated with more than one category, the dominant one was selected. Figure 1 summarizes these results.

This classification reveals that when prompted to identify opportunities to "create positive social change", many of the submissions were not related to social change and changemaking. Seventyfive of the responses were related to economic concerns, weren't engineering practice, or were otherwise not related to the other themes. For example: "Pharmacy allocation" (unclear), and "Maximize multitasking features on a phone to increase productivity" (not related to themes). 


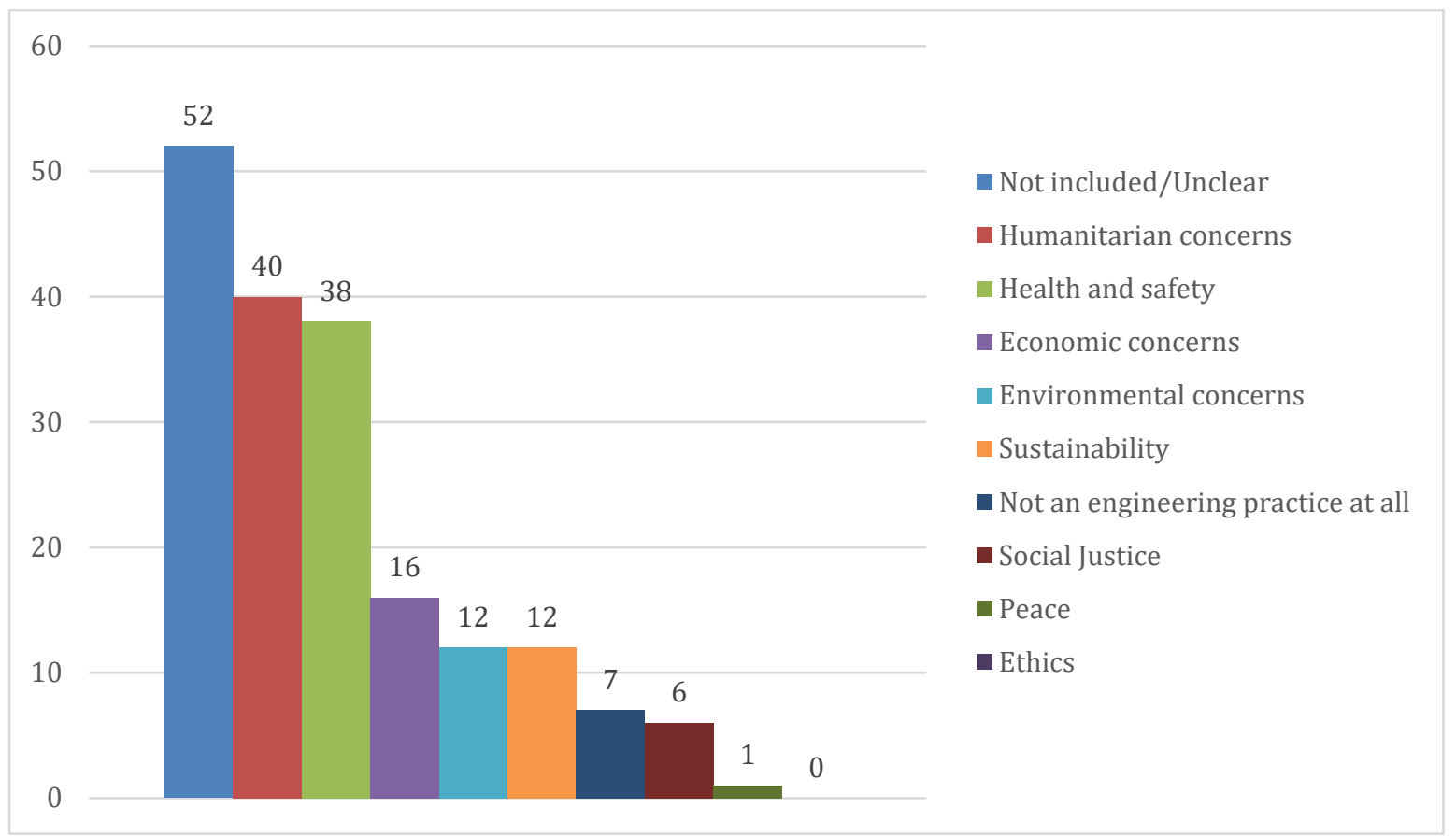

Figure 1. Classification of situations identified by ISYE 340 students in Fall 2017 with respect to changemaking engineering content.

Additionally, some of the health and safety examples targeted practice that we do not consider to be not changemaking such as the spacing of lifeguard stations at a beach, or adding CCTV cameras to reduce crime. Within the categories most directly related with the RED project (Humanitarian concerns, Sustainability, Social Justice and Peace), humanitarian practices (such as emergency relief, food banks and homeless welfare) were identified twice as often as the other areas, combined. Finally, some examples were practices that are not related with engineering (maximize voters who support a candidate). Although these responses were not anticipated, the diversity is consistent with the range of definitions of what constitutes changemaking engineering practice.

More surprisingly, when reviewing the student responses, it also became clear that many examples were not directly related to the operations research, let alone the kinds of deterministic models students had been exposed to in ISYE 340. To explore this, the responses were categorized again into five areas:

- OR-related problems that address RED themes (e.g. creating congressional maps that reduce gerrymandering).

- OR-related problems with a loose societal benefit (e.g. scheduling volunteers for a science fair).

- OR-related problems based in the private/for profit sector (e.g. managing Black Friday inventories).

- Problems related to industrial engineering, but not primarily OR (e.g. reducing food waste).

- Problems not directly related to IE, or OR (e.g. minimizing neighborhood energy use). 
The results are presented in Figure 2.

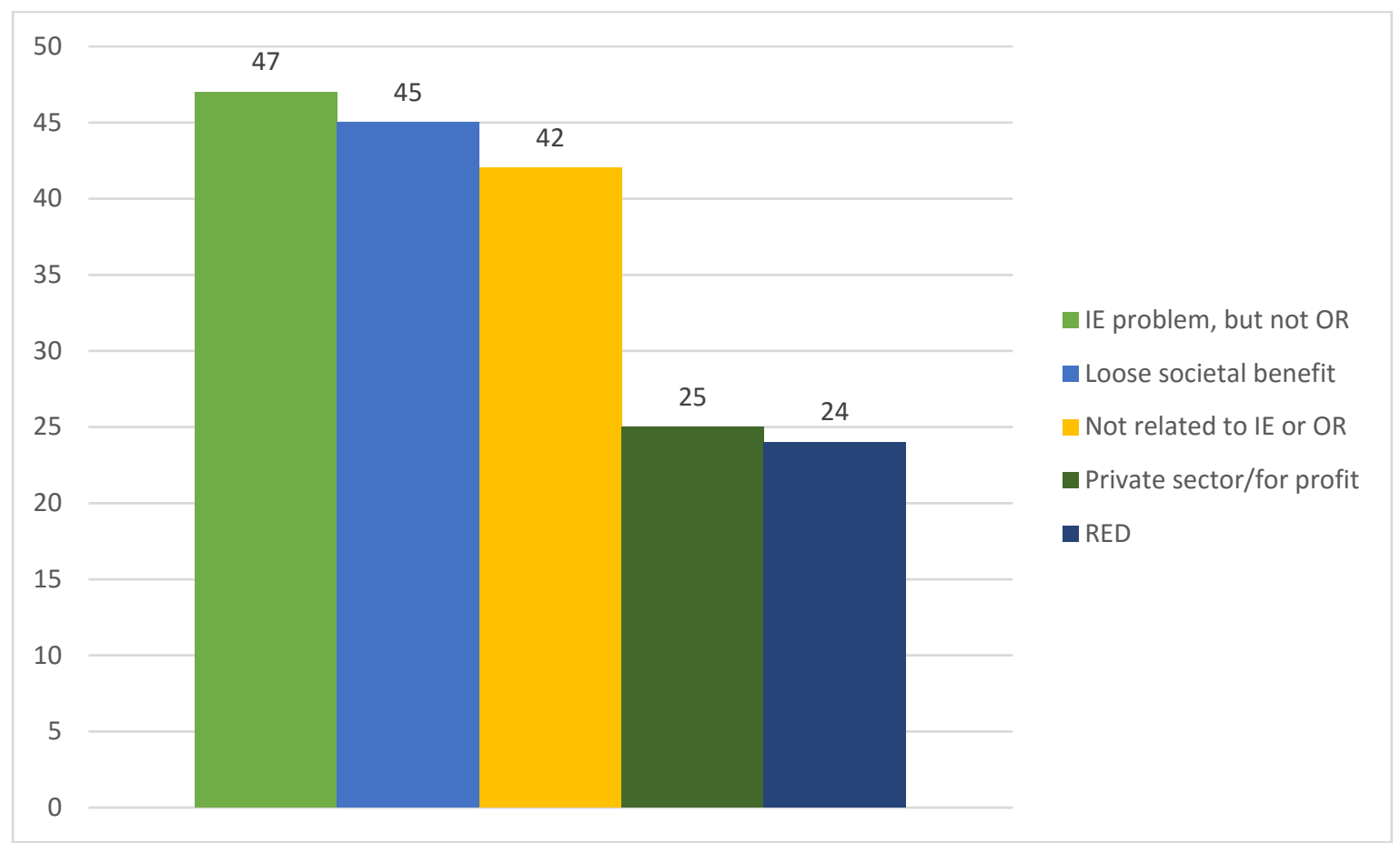

Figure 2. Classification of situations identified by ISYE 340 students in Fall 2017 with respect to operations research and industrial engineering.

In most cases, students clearly identify cases where ISyE methods can be used to solve the problem. However, in many cases, the tools that would be used to address the problem come from engineering economics, ergonomics or general logistics, and would not require operations research methods. For example, "Running registrations logistics for Race for the Cure." In addition, only a few cases are related to the deterministic OR concepts taught in ISYE 340. Others, such as determining the optimal number of servers for a hospital queue, can be solved using other OR methods which students would see in later courses, but had not seen in Fall 2017.

\section{Implications for future classes}

The results of these assignments revealed two main ways in which student understanding did not match expectations. First, their characterization of changemaking engineering did not conform with what was expected from students who have been exposed to USD's changemaking messaging. Caution is necessary when generalizing from this limited sample, but it appears that many students have not formed a mindset that associates engineers and engineering with changemaking potential. Many know that changemakers make society "better", but they were vague about what that means, and they did not connect engineering practice to that improvement.

One likely reason for this is that students have not seen many examples of changemaking engineering. Textbooks, lectures, labs, assignments, and projects emphasize the "technical", equation-oriented aspects of engineering and seldom place the work in any real-world contextlet alone as changemaking. That students on a campus like ours had difficulties relating engineering to changemaking is further evidence of the potential for our RED project to have an impact on engineering education and practice. 
The difficulties that students had in identifying the kinds of problems that can be addressed using OR highlights a different set of problems. Like most first courses in deterministic OR, ISYE 340 begins by focusing on the structure of LPs and the math of the simplex method. Those are in the course objectives. At the end of the course, students are able to demonstrate mastery of those topics. But is that really what is wanted from students who will go on to work as engineers? Few graduates from USD go to graduate school. Even then, a graduate program in ISyE is likely to revisit the math behind LPs in much more detail. In practice, students will use commercial software to solve LPs and perform sensitivity analysis, so an understanding of the simplex method, while intellectually interesting to the faculty, may not be what students need to know to be effective engineers.

In ISYE 340, students are expected to be able to apply and solve allocation, transportation, shortest path and other models. In various assessments they show that they can do that. But the second assignment discussed in this paper shows that students are not always able to identify when OR can be used to address a problem, and, equally importantly, when OR is not the right approach. This likely makes them less effective engineers than they could be.

One strategy for addressing this may be to flip the sequencing of the course topics. Rather than begin with discussions of the geometry of LPs and the simplex method, the first half of the course could emphasize modeling. Students could be introduced to families of models in the context of changemaking and more traditionally ISyE areas. Then, halfway through the course, students could be posed with more open-ended cases that are not correlated with specific lectures. This sequencing would ensure that students have been exposed to the modeling principles needed to handle the broad range of situations they might encounter when addressing changemaking problems. Coming back to these ideas in the second half of the course is also an instance of spaced repetition which will help students to better retain them. Finally, this would spread modeling over the entire semester allowing students to see deterministic OR in more contexts which will help them to construct a better understanding of where it can be used, and where it cannot. It would also allow students to address some of the case topics that were not developed in Fall 2017 because students lacked the background.

With modeling being emphasized in the first part of the semester, the simplex method, and other "math" topics, could be covered in the last half. Lectures and daily assignments would have an algorithmic focus, while modeling-related assignments could continue in parallel.

\section{Conclusion}

The experience of introducing changemaking engineering in ISYE 340 in Fall 2017 had mixed results. Although some of the lectures provided a good opportunity to show students that OR can be applied outside of the business and operations-oriented applications usually presented, students did not express a clear vision of how engineering can lead to changemaking practice. This connection is not something that can be learned by solving homework problems. Rather, engineering programs need to work to highlight the potential of changemaking engineering throughout the engineering curricula. This is the goal of our RED grant. 
The difficulties that some students had in identifying appropriate uses of operations research is a different problem. Its resolution lies in providing opportunities for students to see a wider range of models and for students to be exposed to a greater variety of problem settings. This will allow students to construct their own knowledge that will continue to expand through their engineering practice. But this latter problem is probably not unique to operations research modelling. It is likely that similar "application gaps" occur in many of our courses where faculty teach focused lessons and assume that students will be able to extrapolate that knowledge to new situations that they encounter in their careers. Faculty should question that assumption and work to ensure that students are providing opportunities to make those connections

\section{Acknowledgements}

The authors thank the National Science Foundation's REvolutionizing engineering and Computer Science Departments (RED) program for support of this work (Award 1519453). The views expressed herein are solely those of the authors.

\section{References}

[1] Brown University, About: Swearer Center - College \& University Engagement Initiative, https://www.brown.edu/swearer/carnegie/about, 2017, (accessed January 2018).

[2] Ashoka U, Changemaker Campus, http://ashokau.org/changemakercampus/, (accessed January 2018).

[3] National Science Foundation, IUSE/Professional Formation of Engineers: REvolutionizing engineering and computer science Departments (IUSE/PFE: RED), https:/www.nsf.gov/funding/pgm_summ.jsp?pims_id=505105, 2017, (accessed January 2018).

[4] Lord, S.M., E.J. Berger, N.N. Kellam, E.L. Ingram, D.M. Riley, D.T. Rover, N. Salzman, and J.D. Sweeney, "Talking about a Revolution: Overview of NSF RED Projects," 2017 ASEE Annual Conference \& Exposition, Columbus, OH, June 2017.

[5] Roberts, C., et al., "Work In Progress: Developing Changemaking Engineers (Year 2)," 2017 ASEE Annual Conference and Exposition, Columbus, OH, June 2017.

[6] Winston, W., Operations Research Models: Applications and Algorithms 4th ed., Duxbury Press, Belmont, CA, 2003.

[7] Gregory, A., "R U There?", The New Yorker Magazine, https://www.newyorker.com/magazine/2015/02/09/r-u, February 9, 2015, (accessed October 2017).

[8] Apte, A., Humanitarian Logistics: A New Field of Research and Action, Foundations and Trends in Technology, Information and Operations Management, vol. 3, no. 1, pp. 1-100, 2010.

[9] University of San Diego, Strategic Planning Principles- Envisioning 2024, http://www.sandiego.edu/envisioning-2024/principles/, 2018, (accessed January 2018).

[10] Kabo, J. and C. Baillie, "Seeing through the lens of social justice: a threshold for engineering," Eur. J. Eng. Educ., vol. 34, no. 4, pp. 317-325, 2009.

[11] Slattery, M., and T. Lamb, "Year 2: Evaluation Report for the USD RED Grant on Engineering Changemakers", Peak Research LLC, 2017. 